\title{
EFEITO DA ACIDEZ NA ESTABILIDADE DA CAMADA PASSIVA DE AÇOS INOXIDÁVEIS EM SOLUÇÕES CONTENDO ÍONS CLORETOS
}

Fernanda Martins Sousa Dias' Luiz Cláudio Cândido²

\section{Resumo}

Através de ensaios eletroquímicos de polarização potenciodinâmica caracterizaram-se diferentes sistemas. Avaliaram-se diferentes condições de acidez ( $\mathrm{pH}$ entre 0,0 e 4,0) de soluções aquosas $(\mathrm{I} \mathrm{M} \mathrm{NaCl}+\mathrm{I} \mathrm{M} \mathrm{HCl})$ no comportamento da camada passiva de aços inoxidáveis: ferrítico (AISI 444), austeníticos (AISI 304 e 3 I6L) e duplex ("SAF 2205"), através do levantamento de curvas de densidade de corrente crítica em função de diferentes pHs. Assim, avaliou-se o $\mathrm{pH}$ de depassivação ( $\mathrm{pHd}$ ) a partir do qual os aços sofrem ataque corrosivo acentuado. $\mathrm{O}$ aço "2205" apresentou melhor desempenho com menor pHd e, também, menor densidade de corrente crítica.

Palavras-chave: Aços inoxidáveis; Cloretos; pH de depassivação.

\section{EFFECT OF ACIDITY IN THE STABILITY OF FILM PASSIVE OF STAINLESS STEELS IN SOLUTIONS CONTAINING CHLORIDES}

\begin{abstract}
The systems have been electrochemically characterized through parameters obtained by potenciodynamic polarization tests. The steels employed were AISI 444, 304, 316L and a duplex type "2205". Polarization curves were done using aqueous solutions containing I $\mathrm{M} \mathrm{NaCl}+\mathrm{I} \mathrm{M} \mathrm{HCl}(\mathrm{pH}$ between $\cong 0.0$ and 4.0) at room temperature, and $\mathrm{pH}$ depassivation curves were obtained. The steel duplex "2205" presented the best performance with smaller $\mathrm{pH}$ depassivation.
\end{abstract}

Key words: Stainless steels; Chlorides; pH depassivation.

\section{INTRODUÇÃO}

Nos aços inoxidáveis o cromo contribui para a formação de uma fina camada de filme passivo (alguns nanômetros de espessura), que os protege contra $\circ$ ataque corrosivo. Este filme age como uma camada protetora e reduz drasticamente a transferência de íons metálicos do metal para o meio ambiente. Mesmo quando rompido, este filme se regenera em atmosfera oxidante e mantém a capacidade de proteção à corrosão. ${ }^{(1-5)}$

Em meios com maior concentração de íons cloretos e mais ácidos geralmente ocorre dissolução de cloretos o que não permite a passivação do material. ${ }^{(5)}$ Portanto, os halogenetos, particularmente, os íons cloretos tendem a desestabilizar o filme passivo em aços inoxidáveis.

Avalia-se a estabilidade de filmes passivos através de ensaios eletroquímicos de polarização. $\mathrm{O}$ efeito do $\mathrm{pH}$ pode ser compreendido medindo-se a densidade de corrente crítica (valor máximo na região de ativação) em função do $\mathrm{pH}$. $\mathrm{O}$ pH de depassivação (pHd) é o $\mathrm{pH}$ abaixo do qual a passividade não é estável. De um modo geral, quanto mais baixo é o $\mathrm{pH}$ de depassivação, mais resistente é o material. ${ }^{(5)}$

Ressalta-se que no potencial eletroquímico de transpassivação, as propriedades do filme passivo mudam e a velocidade de dissolução aumenta. Esse comportamento, chamado de depassivação anódica, resulta de uma oxidação do filme passivo ou de interações específicas com certos ânions. ${ }^{(6)}$

A estabilidade de um filme passivo depende fortemente dos elementos de liga presentes no aço. O principal deles é o molibdênio, que tem correlação direta com a maior homogeneidade do filme. Sendo assim, a escolha de um material adequado (baixo $\mathrm{pHd}$, alto potencial de pite em meios ácidos) torna-se fundamental.

\footnotetext{
'Enga Metalúrgica - Escola de Minas/UFOP; Membro da ABM. Morro do Cruzeiro - 35400-000 -Ouro Preto, MG. fernandamsdias@yahoo.com.br ${ }^{2}$ Engo Metal.; M.Sc.; D.Sc; Membro da ABM; Prof. Associado I; Grupo de Estudos sobre Fratura de Materiais; Dep. Eng. Metalúrgica e de Materiais - Escola de Minas/UFOP. Morro do Cruzeiro - 35400-000 - Ouro Preto, MG. candido@em.ufop.br.
} 
Neste trabalho fez-se caracterização eletroquímica de diferentes sistemas (metal/meio), através de curvas de polarização, e obtiveram-se curvas de densidade de corrente crítica $\left(i_{\text {crit }}\right)$ versus $\mathrm{pH}$ das soluções, indicando valores de $\mathrm{pHd}$.

\section{PROCEDIMENTO EXPERIMENTAL}

A partir de chapas de aços inoxidáveis AISI: 304, 316L, 444 e um duplex do tipo "SAF 2205" foram realizados ensaios de polarização potenciodinâmica. As Tabelas I-4 apresentam as composições químicas dos materiais estudados.

Tabela I. Composição química do aço inoxidável austenítico AISI 304 (\% peso).

\begin{tabular}{cccccccc}
\hline $\mathbf{C}$ & $\mathbf{C r}$ & $\mathbf{N i}$ & $\mathbf{M n}$ & $\mathbf{S i}$ & $\mathbf{P}$ & $\mathbf{S}$ & $\mathbf{N}_{2}$ \\
\hline 0,056 & 18,110 & 8,070 & 1,290 & 0,400 & 0,028 & 0,001 & 0,033 \\
\hline
\end{tabular}

Tabela 2. Composição química do aço inoxidável austenítico AISI $316 \mathrm{~L}$ (\% peso).

\begin{tabular}{cccccccc}
\hline $\mathbf{C}$ & $\mathbf{C r}$ & $\mathbf{N i}$ & $\mathbf{M n}$ & $\mathbf{S i}$ & $\mathbf{P}$ & $\mathbf{S}$ & $\mathbf{M o}$ \\
\hline 0,021 & $|7,28|$ & $|1,03|$ & $|, 50|$ & 0,687 & 0,029 & 0,003 & 2,049 \\
\hline
\end{tabular}

Tabela 3. Composição química do aço inoxidável ferrítico AISI 444 (\% peso).

\begin{tabular}{cccccccc}
\hline $\mathbf{C}$ & $\mathbf{C r}$ & $\mathbf{M o}$ & $\mathbf{N b}$ & $\mathbf{T i}$ & $\mathbf{N i}$ & $\mathbf{M n}$ & $\mathbf{C u}$ \\
\hline 0,009 & 17,680 & $\mathrm{I}, 810$ & 0,170 & 0,140 & 0,200 & 0,140 & 0,039 \\
\hline $\mathbf{V}$ & $\mathbf{A l}$ & $\mathbf{C o}$ & $\mathbf{S i}$ & $\mathbf{P}$ & $\mathbf{S}$ & $\mathbf{N}_{2}$ & $\mathbf{O}_{2}$ \\
\hline 0,048 & 0,009 & 0,028 & 0,360 & 0,027 & 0,002 & 0,012 & 0,004 \\
\hline
\end{tabular}

Tabela 4. Composição química do aço inoxidável duplex "SAF 2205" (\% peso).

\begin{tabular}{ccccccccc}
\hline $\mathbf{C}$ & $\mathbf{C r}$ & $\mathbf{M o}$ & $\mathbf{N i}$ & $\mathbf{M n}$ & $\mathbf{S i}$ & $\mathbf{P}$ & $\mathbf{S}$ & $\mathbf{N}$ \\
\hline 0,003 & 23,380 & 2,550 & 5,320 & 1,480 & 0,350 & 0,029 & 0,003 & $0,1 / 2$ \\
\hline
\end{tabular}

Para avaliar as características eletroquímicas dos sistemas, foram realizados ensaios de polarização potenciodinâmica empregando-se um potenciostato tipo Princeton Applied Research - modelo 237A. As amostras, com $1 \mathrm{~cm}^{2}$ de área, foram lixadas até a granulometria número 600 e desengraxadas em acetona e álcool. Os ensaios foram realizados em uma célula eletroquímica do tipo plana, com 3 eletrodos (contra-eletrodo de platina e eletrodo de referência de calomelano saturado), em condições aeradas e na temperatura ambiente. Estabilizou-se o potencial de corrosão (Ecor) durante 3.600 s. A taxa de varredura de potencial eletroquímico foi de $0,166 \mathrm{mV} / \mathrm{s}$.

As soluções empregadas continham I $\mathrm{M} \mathrm{NaCl}$ e foram acidificadas com I M HCl. Foram utilizadas soluções com pH: 0,0; 0,$5 ; 1,0 ; 2,0 ; 3,0 ; 4,0$.

\section{RESULTADOS E DISCUSSÃO}

As Figuras I a 6 mostram curvas de polarização potenciodinâmica nos diferentes sistemas analisados. Nota-se que quanto menor o pH do meio, menor a zona de passivação, maior o grau de corrosão do material, portanto, maior densidade de corrente crítica.

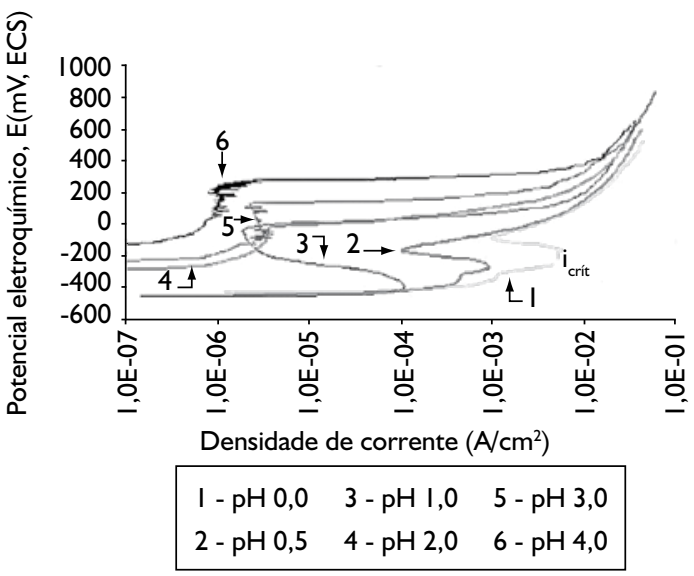

Figura I. Curvas de polarização potenciodinâmica $(0,166 \mathrm{mV} / \mathrm{s})$ para o aço AISI $304 \mathrm{em}$ diferentes $\mathrm{pHs}$ ( $\mathrm{M} \mathrm{NaCl}+$ I $\mathrm{M} \mathrm{HCl}$ ).

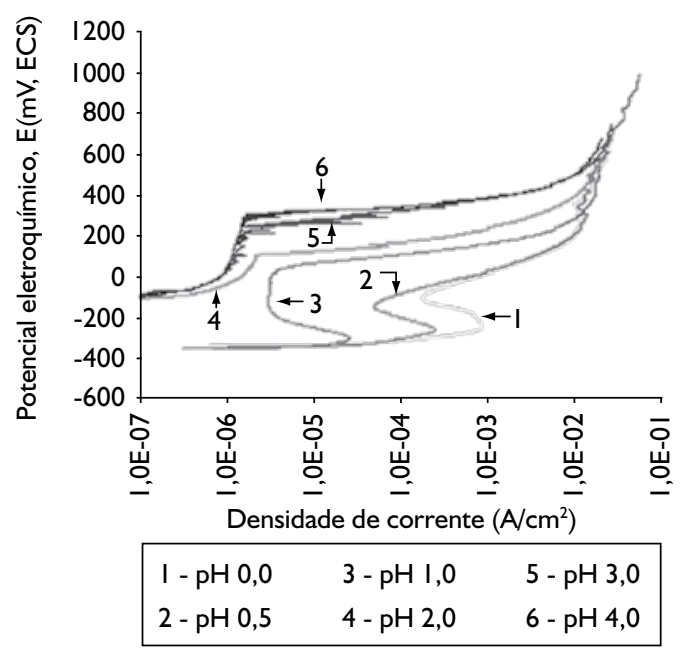

Figura 2. Curvas de polarização potenciodinâmica $(0,166 \mathrm{mV} / \mathrm{s})$ para o aço AISI $316 \mathrm{~L}$ em diferentes $\mathrm{pHs}$ ( $\mathrm{M} \mathrm{NaCl}+$ I $\mathrm{MHCl}$ ).

As Figuras 5 e 6 comparam os quatro aços em termos de desempenho, através de curvas de polarização potenciodinâmica, para $\mathrm{pH}=0,0$ e 4,0. Nota-se o efeito mais agressivo nos aços para meio com $\mathrm{pH}=0,0$, com menores valores de potencial de corrosão. Para esta condição as densidades de corrente são relativamente altas, indicando que os aços não apresentam estabilidade do filme passivo. No caso de $\mathrm{pH}=4,0$ a resistência à corrosão é notada, pois todos apresentam características passivantes, destacando-se maior resistência do aço inoxidável duplex "2205" (ampla zona de passivação) em relação aos outros aços. Isto se deve ao maior teor de cromo e a presença de molibdênio nesta liga.

A partir dos dados obtidos nos ensaios de polarização potenciodinâmica fez-se o levantamento de curvas de densidade de corrente crítica $\left(\mathrm{i}_{\text {crit }}\right)$ versus $\mathrm{pH}$ do meio com objetivo 


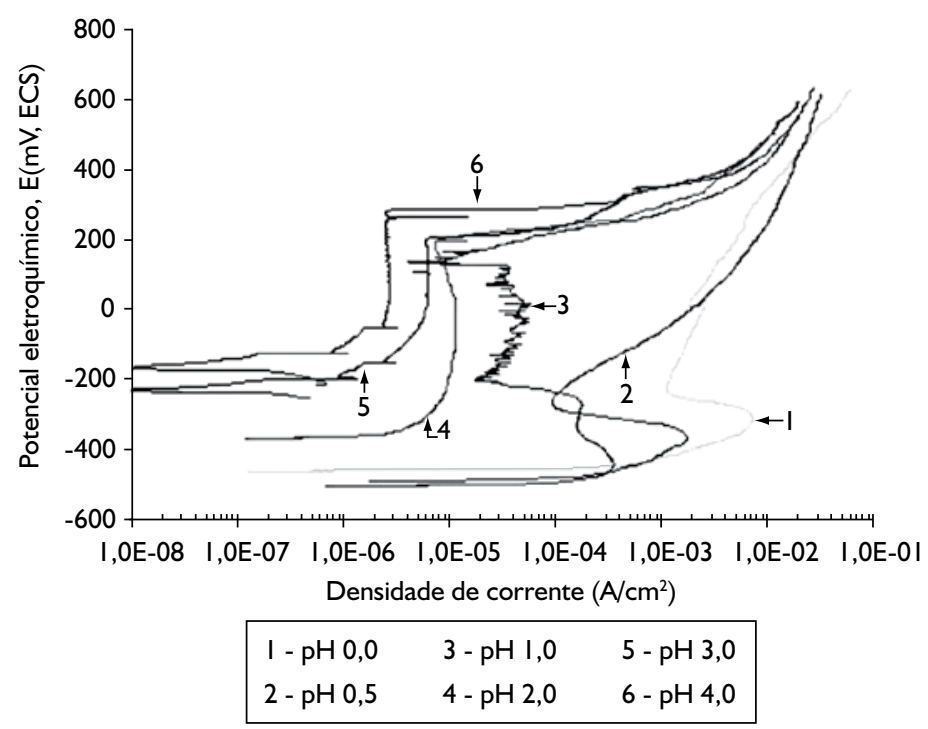

Figura 3. Curvas de polarização potenciodinâmica $(0,166 \mathrm{mV} / \mathrm{s})$ para o aço AISI 444 em diferentes pHs (I M NaCl + I M HCl).

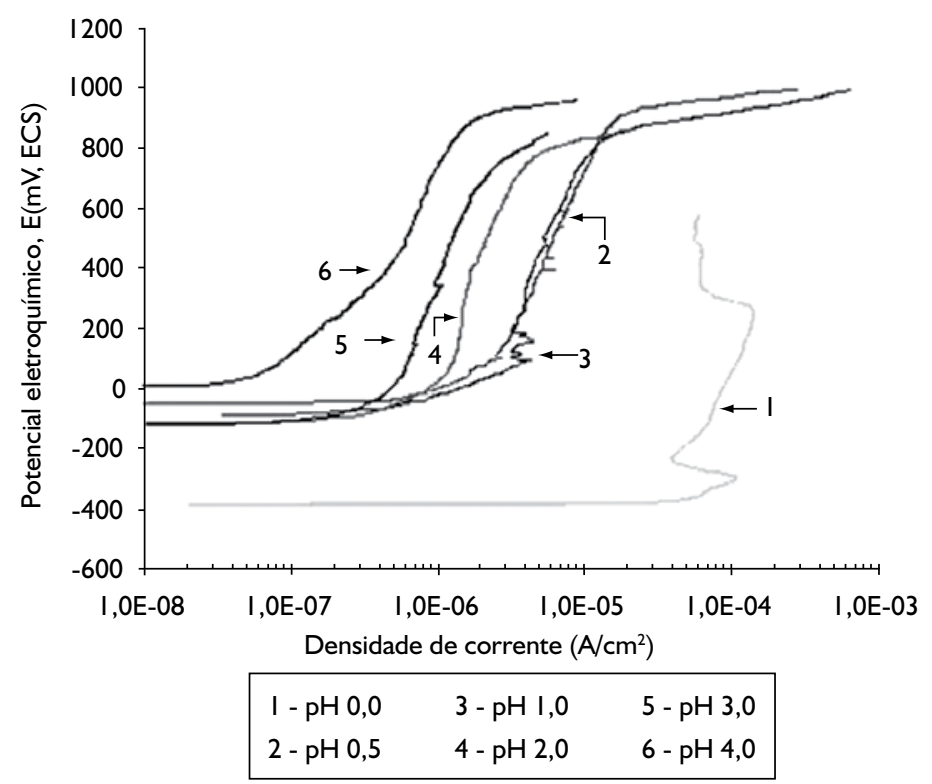

Figura 4. Curvas de polarização potenciodinâmica $(0,166 \mathrm{mV} / \mathrm{s})$ para o aço duplex "2205" em diferentes pHs ( $\mathrm{M} \mathrm{NaCl}+\mathrm{I} \mathrm{M} \mathrm{HCl})$.

de identificar o pH de depassivação ( $\mathrm{pHd}$ ) dos aços (Figura 7). Observa-se que para os aços AISI 304, AISI 3I6L e AISI 444 abaixando-se o $\mathrm{pH}$ até 2,0 os aços apresentam passivação, com certa estabilidade do filme. No entanto, para pHs inferiores ocorre um incremento na $\mathrm{i}_{\text {crit }}$ indicando o $\mathrm{pHd}$, com pior desempenho para o aço AISI 444 (inoxidável ferrítico) em relação aos aços inoxidáveis austeníticos(AISI 304 e AISI 316L). Nota-se, também, o melhor desempenho do aço duplex "2205" (apresenta menores valores de $i_{\text {crit }}$ em todos $\mathrm{pHs}$ ). $\mathrm{E}$, ainda, esta liga apresentou $\mathrm{pHd} \leq \mathrm{I}, 0$ indicando maior estabilidade $\circ$ filme passivo em relação aos outros aços.

Tecnologia em Metalurgia e Materiais, São Paulo, v.4, n.4, p. 43-46, abr.-jun. 2008

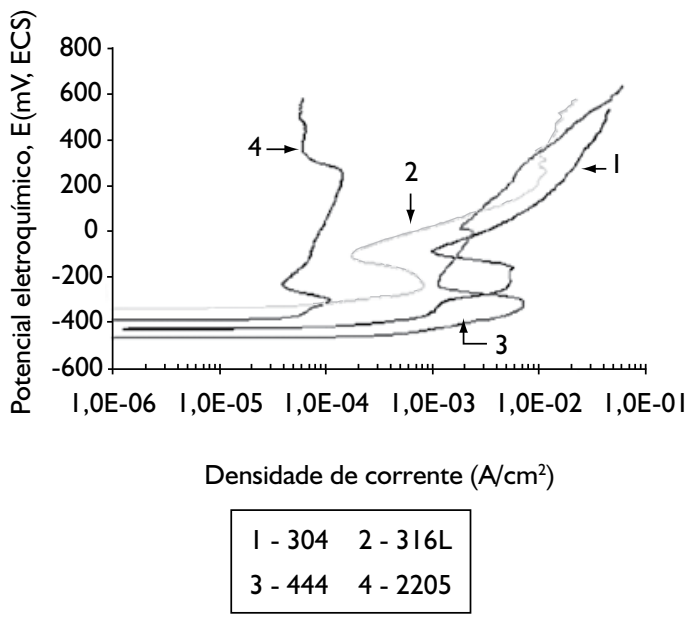

Figura 5. Curvas de polarização potenciodinâmica $(0,166 \mathrm{mV} / \mathrm{s})$ para os aços AISI: 304, $316 \mathrm{~L} \mathrm{e} 444$, e o duplex "2205" em meio com $\mathrm{pH}=0,0$ ( $\mathrm{M} \mathrm{HCl})$.

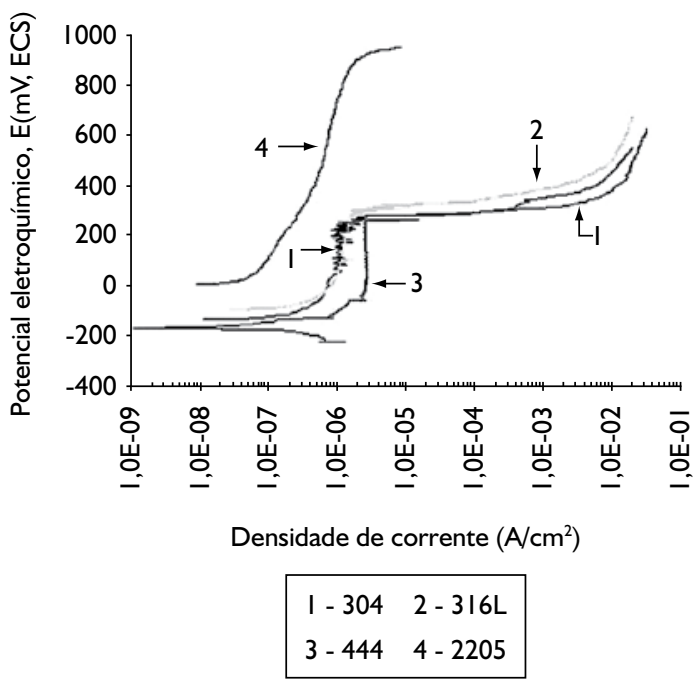

Figura 6. Curvas de polarização potenciodinâmica $(0,166 \mathrm{mV} / \mathrm{s})$ para os aços AISI: 304, 3 I6L e 444, e o duplex "2205" em meio com pH = 4,0 (I M NaCl + I M HCl).

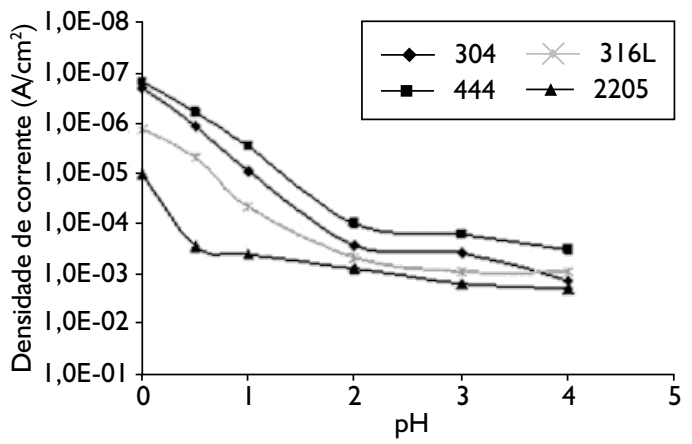

Figura 7. Curvas de densidade de corrente crítica (log) versus $\mathrm{pH}$ (soluções com I $\mathrm{M} \mathrm{NaCl}+\mathrm{I} \mathrm{M} \mathrm{HCl}$ ) para os aços AISI: 304, 316L e 444, e o duplex "2205". 
Miranda e Santandréa ${ }^{(7)}$ avaliaram as características comportamentais de aços inoxidáveis ferríticos, com e sem molibdênio, estabilizados com titânio e nióbio, comparativamente ao aço do tipo AISI 304, em ensaios eletroquímicos onde obtiveram curvas de pHd. Observaram que o desempenho dos aços ferríticos foi função da proporcionalidade de molibdênio na liga. No entanto, a mudança onde ocorreu a instabilidade no filme passivo (incremento no $\mathrm{i}_{\text {crit }}-$ correspondendo ao $\mathrm{pHd}$ ), foi muito acentuada para os aços inoxidáveis ferríticos em relação ao aço inoxidável austenítico. Nota-se na Figura 7 que o aço duplex "2205" apresentou mudança mais brusca apenas em $\mathrm{pH} \cong 0,50$.

Faria ${ }^{(8)}$ também avaliou o $\mathrm{pH}$ de depassivação de quatro aços inoxidáveis ferríticos (tipos ACE/UGI: FI7T; 430E; 439A; 44IA; FI8TNb), estabilizados e não estabilizados com titânio e nióbio. Verificou-se maior $\mathrm{pHd}(\cong 3,05)$ para o aço $430 \mathrm{E}(16 \mathrm{Cr} 4 \mathrm{Nb})$. No entanto, para os outros aços o pHd foi aproximadamente 2,20.

Azuma et al. ${ }^{(9)}$ notaram que adição de níquel em aço inoxidável ferrítico ( $25 \mathrm{Cr} 3 \mathrm{Mo}$ - \% peso) foi efetiva na diminuição do $\mathrm{pHd}$ e na taxa de dissolução em frestas para soluções contendo ácido clorídrico.
Nota-se que os dados obtidos neste trabalho estão de acordo com a literatura mencionada, e que este mostra faixas de $\mathrm{pHs}$ de soluções em que os materiais podem ou não ter um bom desempenho em termos de resistência à corrosão.

\section{CONCLUSÕES}

- Os ensaios de polarização potenciodinâmica mostraram que os aços em meios com $\mathrm{pH} \cong 4,0$ apresentaram características passivantes;

- Em todos os meios analisados o aço do tipo AISI 444 apresentou pior desempenho; contrariamente, o duplex "2205" o melhor; $\mathrm{E}$

- As curvas de $\mathrm{pH}$ de depassivação indicaram que o aço duplex "2205" apresentou $\mathrm{pHd} \leq \mathrm{I}, 0$, o que confirma a presença de molibdênio e o maior teor de cromo na liga.

\section{REFERÊNCIAS}

I CHAWLA, S.L.; GUPTA, R.K. Materials selection for corrosion control. Materials Park, OH: ASM International, 1995.

2 DAVIS, J.R. ASM speciality handbook: stainless steels. Materials Park, OH: ASM International, 1996.

3 SEDRIKS, A.J. Corrosion of stainless steels. 2. ed.[S.I.]: Lavoisier, 1996.

4 GENTIL, V. Corrosão. Rio de Janeiro: Livros Técnicos e Científicos, 2003.

5 MANTEL, M.J.Título do trabalho. In: SEMINÁRIO INOX 2000; 2000. Roças Novas, MG. Anais... Timóteo: Acesita, 2000. p.inicial-p.final

6 GEMELLI, E. Corrosão de materiais metálicos e sua caracterização. Rio de Janeiro:LTC, 200 I.

7 MIRANDA, L.; SANTANDRÉA, R. Corrosão localizada em aços inoxidáveis ferríticos estabilizados. In: CONGRESSO BRASILEIRO DE CORROSÃO, 20.; SEMINÁRIO DE DEGRADAÇÃO DA ABRACO, 2., 2000, Fortaleza, CE. Anais... Rio de Janeiro: Abraço, 2000 . p.inicial-p.final.

8 FARIA, R.A. Efeito dos elementos Ti e Nb no comportamento em fadiga de aços inoxidáveis ferríticos utilizados no sistema de exaustão de veículos automotores. 2006,244p. Tese (Doutorado - Engenharia de Materiais)- Rede Temática em Engenharia de Materiaisda Universidade Federal de Ouro Preto. Ouro Preto, 2006.

9 AZUMA, S.; KUDO, T.; MIYUKI, H.; YAMASHITA, M.; UCHIDA, H. Effect of nickel alloying on crevice corrosion resistance of stainless steels. Corrosion Science, v. 46, n. 9, p. 2265-80, 2004.

Recebido em: 13/12/07

Aceito em: 09/04/08

Proveniente de: CONGRESSO ANUAL DA ABM - INTERNACIONAL, 62., 2007, Vitória, ES.São Paulo: ABM, 2007. 